\title{
Evaluation of postoperative practices by 55 French otologists regarding packing the external auditory canal
}

\author{
Laura Renard $^{1}$, Charles Aussedat ${ }^{2}$, and David Bakhos ${ }^{3}$ \\ ${ }^{1}$ Université de Tours \\ ${ }^{2} \mathrm{CHU}$ de Tours, service ORL et Chirurgie Cervico-Faciale, boulevard Tonnellé, 37044 \\ Tours, France \\ ${ }^{3}$ Université François-Rabelais de Tours, CHRU de Tours, service ORL et CCF, UMR-S930, \\ Tours, France
}

October 28, 2020

\section{Evaluation of postoperative practices by 55 French otologists \\ regarding packing the external auditory canal}

Renard $\mathrm{L}^{1}$, Aussedat $\mathrm{C}^{1,2}$, Bakhos $\mathrm{D}^{1,2,3}$

1472 words/2 figures/2 tables/10 references

\section{Acknowledgements}

The authors thank all the physicians for their participation in the study.

\section{Conflicts of interest and source of funding}

The authors of this research declare that there are no conflicts of interest associated with this publication.

\section{Key points}

1. Packing of the external ear canal was common, but techniques were very heterogeneous.

2. Preferred packing material varied among surgeons, due to lack of recommendation.

3. The most-used packing material was a combination of ear wick and silastic sheet.

4. Most surgeons were reluctant to not pack the external ear canal.

5. Further research is needed to assess the "no packing" technique.

\section{Keywords}

Ear packing; surgery; otology; professional practices

IntroductionPacking of the external auditory canal (EAC) after middle ear surgery is an established practice in many ENT centers. Since the first packing technique was introduced in 1973 using Gelfoam ${ }^{1}$, various types of external ear packing materials have been described $^{2-4}$. While packing material varies among surgeons, the material of choice tends to be based more on tradition than evidence. The theoretical advantages of packing of the EAC are to promote healing of the tympanic eardrum, to support a tympanic graft, and to reposition the tympanomeatal flap in the correct position to avoid EAC stenosis. Packing also aids local hemostasis, helps to avoid lateralization blunting, and improves efficacy of local treatments ${ }^{4}$. 
Packing agents are classified in non-absorbable or absorbable ${ }^{3}$. Non-absorbable packs include hydroxylated polyvinyl acetate (ear wick), silicone sheet, ribbon gauze (with antibiotics, antiseptic ointments, cream or bismuth, iodoform, paraffin paste). Non-absorbable packs need to be removed 7 to 21 days postoperatively, depending on the surgical procedure and the surgeon habits. Removal is usually performed during a clinical visit without anesthesia, except in pediatric and/or anxious patients, in whom inhalation sedation (e.g., nitrous oxide/oxygen premix) can be used ${ }^{5}$. The disadvantages for non-absorbable packs are uncomfortable removal, bleeding, and graft or skin flap displacement following removal ${ }^{4}$. Absorbable packs include short time resorption (8-14 days) for porcine gelatin sponge (Gelitaß) or long-time resorption (8 weeks) for hemostatic collagen compress from veal dermis (Pangen@). While there is none of the pain and discomfort associated with removal of non-absorbable packs, hearing loss and ear fullness can persist for several weeks with absorbable packs ${ }^{6}$.

Most previous otological studies have focused on auditory performance or surgical complications involved with ear packing, but none have reported postoperative surgical habits among physicians. There is currently no consensus regarding ear packing and/or the preferred packing material. As such, there is a need to better understand postoperative practices among surgeons. The aim of this study was to describe practices among French otologists regarding packing of the EAC after otologic surgery procedures. A second objective was to assess physicians' preferences for packing the EAC or not.

\section{Methods}

This study regarding ear-packing habits among French otologists was conducted using an online survey administered between March 15, 2020 and May 15, 2020. Member physicians were recruited from the French Otology and Neurotology Association (AFON), which currently includes 135 members. A Google Forms $\mathbb{R}$ survey was sent to all the members. Participants were asked to indicate their age, experience in otologic surgery, and type of practice (public or liberal). Surgeons with less than 5 years of experience were excluded. The questionnaire included 6 major otological procedures (myringoplasty, ossiculoplasty, canaloplasty, canal wall reconstruction, open and closed tympanoplasty). Participants were asked to describe their surgical approach for each procedure and their postoperative habits (postoperative management, type of packing, time of removal, follow up process) via multiple choice questions. Participants were also asked to express their opinion regarding the absence of packing. The survey can be found at:https://docs.google.com/forms/d/15oFeGalLw43xUpz8CJ9nQI_OFQ7bc2IDKRpTrE4ih9Y/edit . Data available on request from the authors.

\section{Results}

Fifty-seven otologists responded to the survey invitation; two had less than 5 years of experience and were excluded. Thus, a total of 55 responses (11 women) were analyzed, representing $41 \%$ of AFON members; the mean age of the participants was $48.7 \pm 12$ years. Among participants, $67 \%(\mathrm{~N}=37)$ had more than 15 years of otological surgery experience, $35 \%(\mathrm{~N}=19)$ worked in a public hospital, $27 \%(\mathrm{~N}=15)$ had a private practice, and $38 \%(\mathrm{~N}=21)$ had a public/private practice. In terms of clinical practice, $76 \%(\mathrm{~N}=42)$ worked with pediatric and adult patients, with children accounting for $30 \%$ of their practice; 12 participants practiced surgeries only on adults.

Table 1 shows the most frequent approach used by participants for various surgical procedures. Figure 1 shows the different types of ear canal packing used for these procedures. The most frequent packing used was ear wick combined with silicon sheets, ranging from 33\% for Open Technique Tympanoplasty (OTT) to 70\% for Canal Wall Reconstruction (CWR). The second-most popular packing was ear wick for all procedures, ranging from 10-33\%, except for OTT where paraffin gauze accounted for $27 \%$ of the participants' habits. The use of absorbable ear packing ranged from $6 \%$ (canaloplasty) to $22 \%$ (myringoplasty and closed technique tympanoplasty).

-Insert Table 1 
Figure 2 shows the different packing materials used for the various surgical approaches. For $33 \%$ (endaural) to $60 \%$ (transmeatal and enlarged) approaches, the most frequently used ear packing was ear wick combined with silicone sheet. The use of absorbable ear packing ranged from 7\% (enlarged approach) to 26\% (endaural approcach). Among participants, $62 \%$ used the same packing material for all surgical procedures. Among those who varied the packing material according to procedure, $65 \%$ had more than 10 years of otologic experience.

-Insert Figure 2

Table 2 summarizes post-operative management habits. Among participants, 39\% (open tympanoplasty) to $60 \%$ (ossiculoplasty and myringoplasty) prescribed local antibiotics, $78 \%$ (canaloplasty) to $95 \%$ (ossiculoplasty and canal wall reconstruction) prescribed oral analgesic, and 5\% (myringoplasty) to 47\% (open tympanoplasty) prescribed oral antibiotics. Among participants, $75 \%$ performed packing removal 7-10 days after surgery, $11 \%$ after 2 weeks and $7 \%$ before 7 days.

Insert table 2

Nearly all participants $(96 \%)$ were reluctant to provide no packing. The reasons for this reluctance included stenosis of the EAC (26\%), misplacement of the tympanomeatal flap and blunting (7\%), and perturbation of wound healing $(7 \%)$. Some participants also commented on the risk of external contamination, less efficacy of local treatments, and synechia. One participant commented on the increased risk of iatrogenic cholesteatoma, and another reported the risk of filling of the anterior angle.

DiscussionThe present data shows great variability among ENT surgeons regarding ear packing among the procedures analyzed. The most-frequent packing was the combination of ear wick and silicone sheet, but other packing materials were often used. We also found heterogenous habits amongst pre-, peri-, and post-operative management. Nearly all participants were reluctant to proceed after ear surgery without packing.

The heterogeneity in the practices of EAC packing among French ENT surgeons may be explained by the lack of scientific evidence and thus, the lack of recommendation. Only one guideline exists for pediatric populations which recommends the use of resorbable ear pack or a material that allows atraumatic removal ${ }^{7}$. A previous study compared four types of ear packing (paraffine gauze, POP oto wick, silicone sheet and tricortyl ointment) and found no significant difference in terms of pain, discomfort, and postoperative complications (granulation, stenosis, discharge) ${ }^{4}$. While the postoperative practice of packing is widespread, it also presents some drawbacks such as subsequent uncomfortable hearing loss, especially in patients who have a mild hearing loss before the surgery ${ }^{6}$. The removal of the packing can be a source of stress for patients, which may be why the combination of ear wick and silastic was most frequently used. Silastic reduces adhesion to the EAC skin, thereby reducing pain during packing removal, which is ideal for children and/or anxious patients. There is also a lower risk to harm the tympano meatal flap ${ }^{8}$.

A previous pediatric study showed a low rate $(7.5 \%)$ of infection without packing after major ear surgery ${ }^{9}$, as well as better patient satisfaction and cost effectiveness (due to reduced follow-up visits). As such, "no packing" may be advantageous for surgical procedures where the dissection of the tympanomeatal flap is minimal (e.g., stapes surgery or otoendoscopic procedure).

The price of the packing is another consideration, as it differs significantly among ear packing agents For example, in the University of Tours ENT center, prices range from 0,10 \euro (parrafin gauze) to 17,7 euro (silicone sheet). Considering these differences, a medico-economical study would be useful to determine the best ratio between price and efficacy of various packings, and to compare with no packing.

Some study limitations should be discussed. First, while the number of responses may seem limited $(\mathrm{N}=55)$, it represents $41 \%$ of the AFON members. Still, with this limited number of participants, a large variability of ear packing management was demonstrated. The percentage of respondents is comparable to the percentage of people who generally reply to online questionnaires $(40 \%)^{10}$. Another limit was the questionnaire, which 
required participants to indicate their most frequent surgical approach from among 6 choices, rather than an exhaustive report of surgical approaches.

\section{Conclusion}

This study shows the lack of standardization for the packing of the EAC. In future studies, a randomized controlled trial with a large number of patients should be conducted to produce recommendations regarding type of packing, as well as general and local treatments according to the surgical procedure. Other studies should evaluate no packing for surgeries with a small dissection of the tympano-meatal flap.

\section{References}

Holzer F. The fate of gelatin film in the middle ear. Arch Otolaryngol . 1973;98(5):319-321

Javed F, Clark M. The non-stick triple wick; ear canal packing after middle ear surgery. Clin Otolaryngol . 2014;39(6):398-399

Shen Y, Teh BM, Friedland PL, Eikelboom RH, Atlas MD. To pack or not to pack? A contemporary review of middle ear packing agents. Laryngoscope . 2011;121(5):1040-1048

Zeitoun H, Sandhu GS, Kuo M, Macnamara M. A randomized prospective trial to compare four different ear packs following permeatal middle ear surgery. J Laryngol Otol . 1998;112(2):140-144

Hennequin M, Collado V, Faulks D, Koscielny S, Onody P, Nicolas E. A clinical trial of efficacy and safety of inhalation sedation with a $50 \%$ nitrous oxide/oxygen premix (Kalinox) in general practice. Clin Oral Investig . 2012;16(2):633-642

Cho YS, Lee HS, Hong SH, Chung WH, Min JY, Hwang SJ. Effects of packing on the postoperative hearing after middle ear surgery. Acta Otolaryngol Suppl . 2007;(558):67-72

Denoyelle F, Darrouzet V; Societe Francaise d'Oto-Rhino-Laryngologie \& de Chirurgie de la Face et du cou. Recommandations pour la pratique clinique: traitement chirurgical des perforations tympaniques de l'enfant [Clinical practice guidelines: surgical treatment of tympanic membrane perforations in children]. Rev Laryngol Otol Rhinol (Bord) . 2004;125(1):3-16

Minoda R, Haruno T, Miwa T, Kumai Y, Sanuki T, Yumoto E. External auditory canal stenting utilizing a useful rolled, tapered silastic sheet (RTSS) post middle ear surgery. Auris Nasus Larynx . 2010;37(6):680-684

Borgstein J, de Zwart G, Bruce IA. Ear packing after ear surgery: is it really necessary?. J Laryngol Otol . 2008;122(3):253-254

Ekman A, Dickman PW, Klint A, Weiderpass E, Litton JE. Feasibility of using web-based questionnaires in large population-based epidemiological studies. Eur J Epidemiol . 2006;21(2):103-111

Figure legends

Figure 1: Ear packing according to surgical procedure. This histogram illustrates the variability in habits across surgeons, and shows that ear wick combined with silicone sheet was the most frequently used packing material.

Figure 2: Ear packing according to surgical approach. As in Figure 1, the combined ear wick and silicone sheet was the most frequently used packing material.

\section{Hosted file}

Table 1-.pdf available at https://authorea.com/users/371071/articles/489540-evaluation-ofpostoperative-practices-by-55-french-otologists-regarding-packing-the-external-auditorycanal 
Ear packing according to surgical procedure

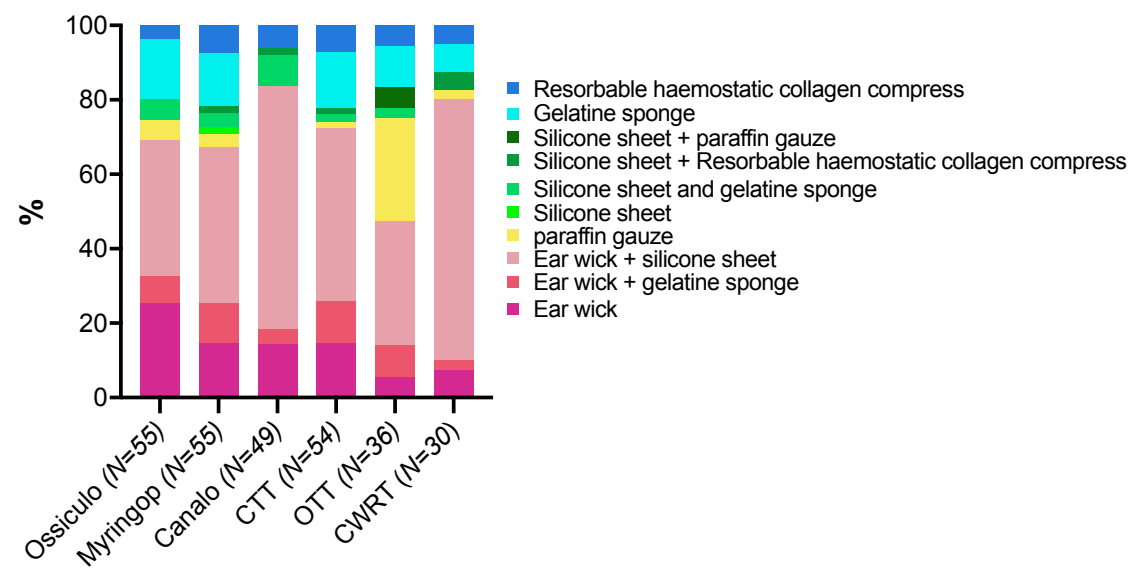




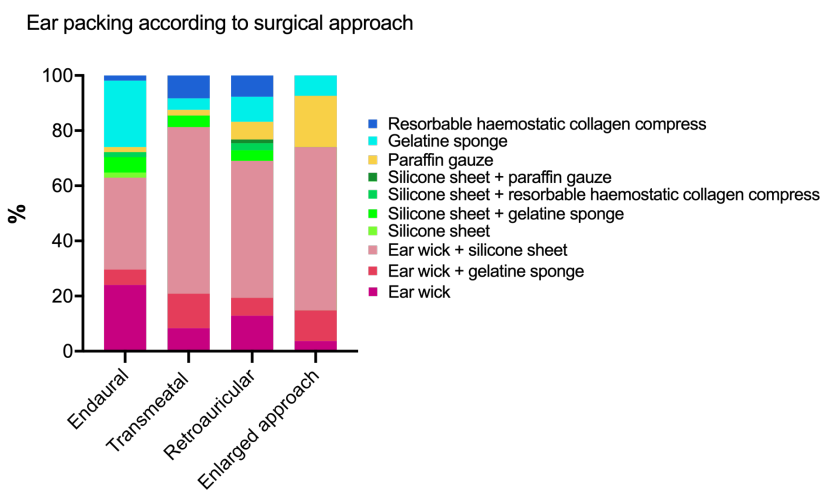

\section{Hosted file}

Table 2-.pdf available at https://authorea.com/users/371071/articles/489540-evaluation-ofpostoperative-practices-by-55-french-otologists-regarding-packing-the-external-auditorycanal 